\title{
Current approach for urinary system stone disease in pregnant women
}

\author{
Orcun Celik, Hakan Türk, Ozgur Cakmak, Rahmi Gokhan Ekin, Mehmet Zeynel Keskin, \\ Guner Yildiz, Yusuf Ozlem Ilbey
}

Urology Department, Tepecik Educational and Research Hospital, İzmir, Turkey.

\begin{abstract}
Summary Urinary system stones can be classified according to size, location, X-ray characteristics, aetiology of formation, composition, and risk of recurrence. Especially urolithiasis during pregnancy is a diagnostic and therapeutic challenge. In most cases, it becomes symptomatic in the second or third trimester. Diagnostic options in pregnant women are limited due to the possible teratogenic, carcinogenic, and mutagenic risk of foetal radiation exposure. Clinical management of a pregnant urolithiasis patient is complex and demands close collaboration between patient, obstetrician and urologist. We would like to review current diagnosis and treatment modalities of stone disease of pregnant woman.
\end{abstract}

KEY WORDS: Urinary stone disease; Pregnancy; Hydronephrosis; Renal colic.

Submitted 5 January 2015; Accepted 31 March 2015

\section{INTRODUCTION}

Urinary system stone disease affects $10 \%$ of the population in a life time. The increase in this rate in the last decade is attributed to the developing imaging methods and more frequent use of imaging as well as to dietary habits, changing climate conditions, increasing obesity and diabetes mellitus (DM) (1-4). Although urinary stone disease used to be more widespread amongst men, the difference between genders disappeared with the increase of urinary system stone incidence in women (2, 5). Urinary stone disease is observed in one in 500 pregnant women, but there is no difference in prevalence when pregnant and non-pregnant groups of similar age are compared (6-13).

In pregnant women, the most noticeable cause of admission to hospital for non-obstetric purposes is urinary system stone disease $(14,15)$. The causes of this condition are the anatomical and physiological changes observed in pregnant women in the structure of urinary system and in the chemical properties of urine. These changes were summarized in the Table 1. Increasing progesterone causes dilatation in the smooth muscles of urinary system and dilation and stasis occur in the urinary system as a result of mechanical pressure from the fetus. Increasing glomerular filtration, calcium supple- ment treatments and increased vitamin $\mathrm{D}$ level increase calcium excretion in the urine (13, 16-25). Furthermore, uric acid, sodium, oxalate and other lithogenic factors show increase during pregnancy $(7,19,20)$. Calcium phosphate stones are observed in $75 \%$ of the pregnant women, whereas in general population usually calcium oxalate stones are prevalent $(10,14,26-31)$.

Urinary stone disease involves some risks for the pregnant woman and her fetus. Though data are contradictive, preterm delivery, miscarriage, premature rupture of membrane, recurrent miscarriages and preeclampsia might be included among these risks (9, 11, 31-36). Importance of diagnosis and treatment of urinary stone disease is evident considering the complications that might be encountered.

\section{Diagnosis}

The gold standard for the diagnosis of urinary stones in non-pregnant patients is computed tomography (37-42). However, its application in pregnant women is limited due to teratogenic effects of radiation. Therefore, the most appropriate first-choice diagnostic tool in pregnant women, despite its 60-78\% sensitivity, is gray scale ultrasonography (USG) (43-46). Ureteral stones might be difficult to demonstrate with USG given to their localization; in this case, assessing resistive index (RI) (> 0.70) with Doppler USG (cDUSG), whose popularity has increased in recent years, will drive the sensitivity up to $90 \%$ in order to display the presemce of obstruction (although the stone cannot be shown) $(47,48)$.

Although RI evaluation will not reveal the cause of obstruction, it is crucial in terms of showing the necessity of intervention. In pregnancy, dilation is observed three times more in the right kidney than it is in the left and it mostly occurs in the mid-trimester. Reasons for more frequent observation of dilation in the right kidney might be listed as: sigmoid colon's relative protection of the left ureter from pressure in the left side, high stress and pressure in the right ureter due to the more proximal intercrossing of iliac veins by right ureter and as the most important factor, dextro-rotation of growing uterus in midtrimester (49-50). Transvaginal USG might also be useful in distinguishing this physiological hydronephrosis, observed almost in 90\% of the pregnant women, from 
ureter stones in the distal part of ureter $(13,23,51)$. If the accuracy of diagnosis is doubted, then Magnetic Resonance Urography (MRU) can be used as a second option. MRU is comparable to $\mathrm{CT}$ and has the advantage of requiring safe and effective contrast media (52-55). At MRU, stones appear as storage defects and at the same time MRU may inform the physician of other causes that might lead to obstruction and about organs outside the urinary system. Popularity of low dose CT (0.97-1.9 $\mathrm{mSv}$ ) with decreased radiation risk, as a last resort, has been increasing in the last years due to its high sensitivity (96.6\%) and specificity (94.9\%) (56-60). Their insufficiency in diagnosis and the risk of complications they trigger during pregnancy, limit the use of direct urinary system graphy (DUSG), intravenous urography (IVU), scintigraphic methods and magnetic resonance imaging (MRI) (31, 61-65). As above reported, the sensitivity and specificity of imaging methods that can be applied during pregnancy are inadequate and the risks of those with high sensitivity limit their use during pregnancy. Because of these reasons, urinary stone disease in pregnant women is already complicated at the stage of diagnosis. In a study, the rate of negative ureteroroscopy (URS) in pregnant women was found to be 14\% (66). Since the physiologic dilation (depending on fetal pressure especially in the right side) can be misdiagnosed as obstruction by a stone of the distal part of the ureter, the role of imaging methods become prominent to avoid invasive procedures based on false positive and the complications that could occur as a result.

\section{TREATMENT MODALITIES}

Due to potential complications, diagnosis and treatment of urinary system stone disease in pregnant women should be closely followed with a multidisciplinary approach by an urologist, a neonatologist, an anesthetist and an obstetrician. In order to minimize the complications, the primary method should be the conservative treatment. In a study conducted by Skolarikos et al., conditions that make patients eligible for conservative treatment are listed as: single stone, smaller than $1 \mathrm{~cm}$ and with no infection; effective pain management and conserved oral intake (67). Most of the pregnant women with kidney stone can receive conservative treatment $(17,68,69)$. Ureter stones become symptomatic mostly in the midtrimester and this necessitates an intervention $(45,70)$. In non-pregnant patients spontaneous passage is reported to be $68 \%$ in patients with $<5 \mathrm{~mm}$ stone size and $47 \%$ in those with $>5 \mathrm{~mm}$ stone size (71), whereas during pregnancy spontaneous passage rate is $70-80 \%$, with some women experiencing spontaneous passage after delivery at a rate of $50 \%(17,11,31,34,36,69,72$, 73). Although some authors argue that spontaneous passage during pregnancy would be higher due to physiologic ureteral dilatation, there are others who think otherwise (10). Because of the limitations in diagnostic methods, the rate of false positive results is high and is reported as high as $23 \%$ according to the results of a study (74). For this reason, they argued that the high rate of spontaneous passage is based on misdiagnosis. In conservative approache, patients must be attentively fol- lowed with physical examination, vital findings, total blood count, blood biochemistry and USG.

\section{a) MET (Medical Expulsive Therapy)}

In addition to conservative treatment, spontaneous passage rate can be increased by medical expulsive therapy (MET) in these patients. As a part of MET, alpha blockers and calcium channel blockers can be safely used during pregnancy (75).

As some patients are not eligible for MET and conservative treatment, the treatment may also fail in others who fit. In particular, fever, infection and obstetric complications are indicative of intervention to the stone. Also solitary kidney or occurrence of bilateral obstruction necessitate immediate intervention. Finally, intervention must be taken into account in the case of intractable pain, oral intake problems and stones that are larger than $1 \mathrm{~cm}$ (76). Cardio-pulmonary changes during pregnancy and limitations in imaging further complicate treatment environment (17). Therefore, intervention team must be composed of an experienced urologist, an obstetrician, a neonatologist, a radiologist and an anesthetist and the patient should be closely followed and monitored.

Intervention is necessary in aforementioned conditions, however, another crucial point is whether it will be a temporary drainage or a definitive treatment. Moreover, the question of whether the percutaneous drainage or the retrograde ureteral stenting is more convenient needs to be answered. With the technological advances in recent years definitive treatment became more prominent and ureterorenoscopy (URS) too is more frequently preferred $(17,77)$. However, extracorporeal shock wave lithotripsy (ESWL) and percutaneous nephrolithotomy (PCNL) are still contraindicate in pregnant women (78-80).

\section{b) URS (Ureterorenoscopy)+Lithotripsy}

Endourologic intervention is being increasingly preferred in line with the fast development of endourology in concert with technological advances. With the miniaturization of URS and enhancement of imaging quality, use of baskets, stone cone and lasers to this process was accelerated. In addition to this, development of monitoring methods used in post-operative follow-up of the patient and fetus also contributes to the process. Besides all these developments, the risk of surgery and the complexity of the procedure should be kept in mind and shared explicitly with the patients. If the definitive treatment is decided, an experienced team, new equipment and post-operative monitoring must be provided.

URS, which is a definitive treatment method, can be applied under spinal or general anesthesia and is a successful procedure considering the results. In a meta-analysis of 14 studies, complication rates of 108 pregnant women who were administered URS were found similar with that of general population and as a consequence the safety and efficiency of URS during pregnancy was highlighted (81). In recent years, records of pregnant women who were administered URS were published and results were reported in Table 2 (26, 82-87). Furthermore, a study carried out by Johnson et al. involving 46 patients reported 2 premature labors, one resulting in delivery (86). If the patient suffers from an active infection or has 


\section{Table 1.}

Physiologic changes in the kidney occurring during pregnancy.

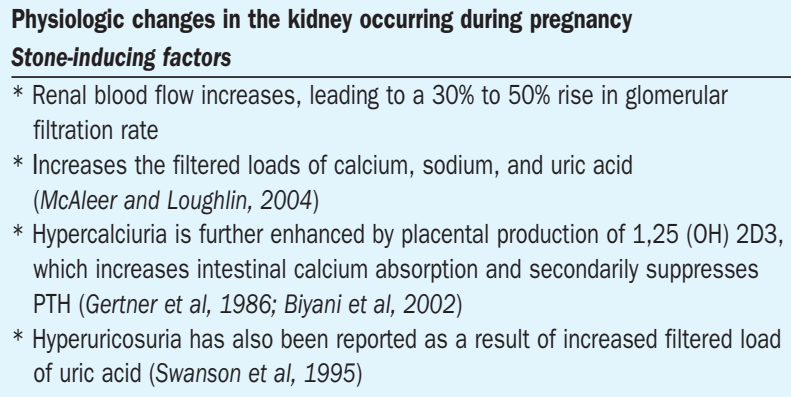

\section{Table 2.}

Complication rates of ureteroscopy during pregnancy.

\begin{tabular}{|lcc|}
\hline Literature & Patients (N) & Complications N (\%) \\
\hline Semins et al. (81) Meta-analysis of 14 studies & 108 & $9(8.3)$ - ureteral perforation (1), premature contractions (1), postoperative pain (2), UTI (5) \\
\hline Travassos et al. (83) & 9 & 0 (0) \\
\hline Rana et al. (84) & 19 & $0(0)$ \\
\hline Polat et al. (82) & 8 & $0(0)$
\end{tabular}

fever, URS is contraindicate because in this case applying a procedure that would drive up the pressure in collecting tubules would aid to infection's progress, and therefore the obstructed system must be immediately drained. Temporary drainage methods should also be applied in case of oversized stone, complex anatomy, bilateral obstruction, obstetric complications, first trimester and being close to delivery $(77,88)$. In deciding the method, experience of the physician, preference of the patient and the available options are to be considered.

\section{c) Temporary Drainage: Percutaneous Nephrostomy (PCN) or Double J Stenting (DJS)}

DJS and USG with PCN are the most frequently employed methods in the treatment of urinary obstructions $(89,90)$. Despite its advantages such as only requiring quick and minimal anesthesia, temporary drainage also has many disadvantages. In addition to inadequacy of temporary drainage in comparison to definitive treatment, disruption of the treatment, as the family focuses on the child, may also result in forgotten stent cases. Physiologic changes during pregnancy involve the necessity of multiple procedures because encrustation of the catheter is accelerated requiring substitution every 4-6 weeks (91-93). This drives up the cost and endangers both the mother and the fetus.

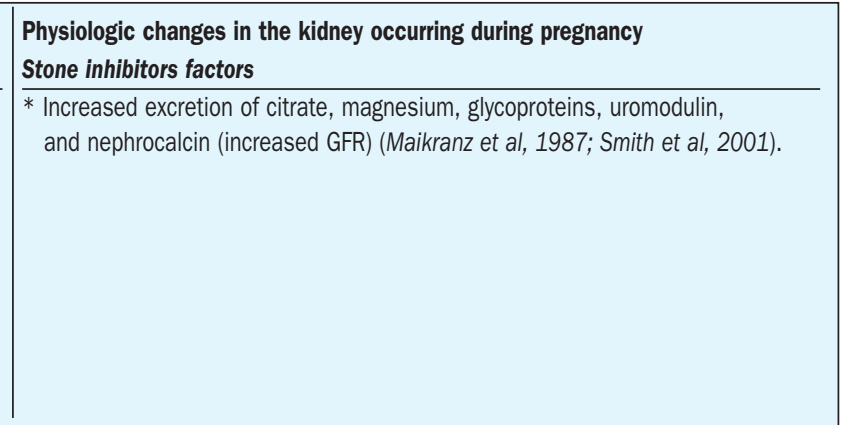

Inability to tolerate temporary drainage, catheter migration and bacterial colonization makes it sometimes unbearable for the patient.

Percutaneous nephrostomy is a procedure first described by Goodwin et al. in 1955 (94). Up to today, it is effectively used under local anesthesia with $98-100 \%$ success rate in obstructed systems (95). Major complication rate of PCN is $6 \%$ whereas minor complication rate is about $28 \%$ (96). According to these rastes, it is not at all an harmless procedure. Therefore, patients that will undergo this procedure must be chosen with caution. If PCN has to be placed in an obstructed and infected system, a wide spectrum antibiotic treatment (ampiciline-sulbactam) is mandatory, in other cases a prophylaxis with first-generation cephalosporin is indicated $(97,98)$.

Important advantages of PCN are the absence of lower urinary system complaints and provides access for later definitive treatment $(17,99)$.

DJS can be applied with $94.2 \%$ success rate with local anesthesia (100). General opinion is that DJS would be more tolerated since it cannot be viewed outside the body by the patient, however it is disadvantageous in terms of causing lower urinary system complaints. Because it could be blocked and bacterial colonization could occur, DJS must be changed every 4-6 weeks (9193). In fact DJS encrustation and stone formation are

\section{Table 3.}

Advantages of DJS and PCN.

\section{DJS}

1. Catheters cannot be observed outside the body

2. Lesser risk of hemorrhage $(5 \mathrm{C})$

3. Interventional radiologist is not needed, any urologist can apply

4. No need for anesthesia

\section{PCN}

1. Catheters can be placed in different sizes (8-12 Fr)

2. Catheter can be irrigated

3. Urine can be followed from the implanted kidney

4. Ureteral complications can be avoided

5. Placement can be made with local anesthesia 
usually seen in patients that had the stent for more than 3 months (89).

Similar results were reported in studies that compare the success of DSJ and PCN (101) and advantages of DSJ and $\mathrm{PCN}$ were listed in Table 3.

Disadvantages of temporary drainage methods emphasize the importance of definitive treatment. However, the most important factors in deciding the treatment are assessing the patient, considering the contraindications, experience of the physician and patient's decision on treatment made in full awareness of the risks (77).

\section{Conclusion}

Both the diagnosis and the treatment of urinary system stone disease is difficult during pregnancy. In deciding the treatment, success of the method, its convenience and the risks that the mother and fetus may suffer from must be considered. After these considerations, patients must be informed of all possible risks, and decision should be made by taking into account the experience of the physician, available equipment and preference of the patient. Even when all the conditions are favorable, natural complications of patient population must be regarded and attentively followed.

\section{References}

1. Pearle MS, Calhoun EA, Curhan GC. Urologic Diseases of America Project. Urologic diseases in America project: urolithiasis. J Urol. 2005; 173:848-857.

2. Odvina CV, Pak CYC. Medical evaluation of stone disease. In: Stoller ML, Meng MV, editors. Urinary Stone Disease: A The Practical Guide to Medical and Surgical Management (Current Clinical Urology). Totowa, NJ: Humana Press Inc. 2007; 259-268.

3. Asplin JR. Obesity and urolithiasis. Adv Chronic Kidney Dis. 2009; 16:11-20.

4. Scales CD Jr, Smith AC, Hanley JM, Saigal CS. Urologic Diseases in America Project. Prevalence of kidney stones in the United States. Eur Urol. 2012; 62:160-165.

5. Scales CD Jr, Curtis LH, Norris RD, et al. Changing gender prevalence of stone disease. J Urol. 2007; 177:979-982.

6. Dudley A, Riley J, Semins MJ. Nephrolithiasis and Pregnancy: Has the Incidence Been Rising? American Urological Association, Abstract \#. 2013:68.

7. Maikranz P, Coe FL, Parks JH, Lindheimer MD. Nephrolithiasis and gestation. Bailleres Clin Obstet Gynaecol. 1987; 1:909-919.

8. Maikranz P, Lindheimer MD, Coe F. Nephrolithiasis in pregnancy. Bailleres Clin Obstet Gynaecol. 1994; 8:375-386.

9. Rosenberg E, Sergienko R, Abu-Ghanem S, et al. Nephrolithiasis during pregnancy: characteristics, complications, and pregnancy outcome. World J Urol. 2011; 29:743-747.

10. Meria P, Hadjadj H, Jungers $P$, et al. Stone Formation and Pregnancy: Pathophysiological Insights Gained From Morphoconstitutional Stone Analysis. J Urol. 2010; 183:1412-1418.

11. Drago JR, Rohner TJ Jr, Chez RA. Management of urinary calculi in pregnancy. Urology. 1982; 20:578-581.

12. Rodriguez PN, Klein AS. Management of urolithiasis during pregnancy. Surg Gynecol Obstet. 1988; 166:103-106.
13. Gorton E, Whitfield HN. Renal calculi in pregnancy. Br J Urol. 1997; 80(Suppl 1):4-9.

14. Horowitz E, Schmidt JD. Renal calculi in pregnancy. Clin Obstet Gynecol. 1985; 28:324-338.

15. Strong DW, Murchison RJ, Lynch DF. The management of ureteral calculi during pregnancy. Surg Gynecol Obstet. 1978; 146:604-608.

16. Resim S, Ekerbicer HC, Kiran G, et al. Are changes in urinary parameters during pregnancy clinically significant? Urol Res. 2006; $34: 244-248$.

17. Srirangam SJ, Hickerton B, Van Cleynenbreugel B. Management of urinary calculi in pregnancy: a review. J Endourol. 2008; 22:867-875.

18. Ritchie LD, Fung EB, Halloran BP, et al. A longitudinal study of calcium homeostasis during human pregnancy and lactation and after resumption of menses. Am J Clin Nutr. 1998; 67:693-701.

19. Maikranz P, Holley JL, Parks JH, et al. Gestational hypercalciuria causes pathological urine calcium oxalate supersaturations. Kidney Int. 1989; 36:108-113.

20. Smith C, Kristensen C, Davis $M$, et al. An evaluation of the physicochemical risk for renal stone disease during pregnancy. Clin Nephrol. 2001; 55:205-211.

21. Conrad KP, Lindheimer MD. Renal and cardiovascular alterations. In: Lindheimer MD, Roberts JM, Cunningham FG, editors. Chesley's Hypertensive Disorders in Pregnancy. 2nd ed. Stamford, CT: Appleton and Lange; 1999. p. 263-326.

22. Gabert HA, Miller JM Jr. Renal disease in pregnancy. Obstet Gynecol Surv. 1985; 40:449-461.

23. Marchant DJ. Effects of pregnancy and progestational agents on the urinary tract. Am J Obstet Gynecol. 1972; 112:487-501.

24. Buppasiri $P$, Lumbiganon $P$, Thinkhamrop J, et al. Calcium supplementation (other than for preventing or treating hypertension) for improving pregnancy and infant outcomes. Cochrane Database Syst Rev. 2011; 10:CD007079.

25. Imdad A, Bhutta ZA. Effect of calcium supplementation during pregnancy on maternal, fetal and birth outcomes. Paediatr Perinat Epidemiol. 2012; Suppl 1:138-152.

26. Ross AE, Handa S, Lingeman JE, et al. Kidney stones during pregnancy: an investigation into stone composition. Urol Res. 2008; 36:99-102.

27. Costa-Bauzá A, Ramis M, Montesinos V, et al. Type of renal calculi: variation with age and sex. World J Urol. 2007; 25:415-421.

28. Gault MH, Chafe L. Relationship of frequency, age, sex, stone weight and composition in 15,624 stones: comparison of resutls for 1980 to 1983 and 1995 to 1998. J Urol. 2000; 164:302-307.

29. Parks JH, Worcester EM, Coe FL, et al. Clinical implications of abundant calcium phosphate in routinely analyzed kidney stones. Kidney Int. 2004; 66:777-785.

30. Cass AS, Smith CS, Gleich P. Management of urinary calculi in pregnancy. Urology. 1986; 28:370-372.

31. Stothers L, Lee LM. Renal colic in pregnancy. J Urol. 1992; 148:1383

32. Banhidy F, Acs N, Puho EH, et al. Maternal kidney stones during pregnancy and adverse birth outcomes, particularly congenital abnormalities in the offspring. Arch Gynecol Obstet. 2007; 275:481-487.

33. Cormier CM, Canzoneri BJ, Lewis DF, et al. Urolithiasis in 
pregnancy: Current diagnosis, treatment, and pregnancy complications. Obstet Gynecol Surv. 2006; 61:733-741.

34. Lewis DF, Robichaux AG, Jaekle RK, et al. Urolithiasis in pregnancy. Diagnosis, management and pregnancy outcome. J Reprod Med. 2003; 48:28-32.

35. Hendricks SK, Ross SO, Krieger JN. An algorithm or diagnosis and therapy of management and complications or urolithiasis during pregnancy. Surg Gynecol Obstet. 1991; 172:49.

36. Swartz MA, Lydon-Rochelle MT, Simon D, et al. Admission for nephrolithiasis in pregnancy and risk of adverse birth outcomes. Obstet Gynecol. 2007; 109:1099.

37. Sourtzis S, Thibeau JF, Damry N, et al. Radiologic investigation of renal colic: unenhanced helical CT compared with excretory urography. AJR Am J Roentgenol 1999; 172:1491-4.

38. Miller OF, Rineer SK, Reichard SR, et al. Prospective comparison of unenhanced spiral computed tomography and intravenous urogram in the evaluation of acute flank pain. Urology 1998; 52:982-7.

39. Yilmaz S, Sindel T, Arslan G, et al. Renal colic: comparison of spiral CT, US and IVU in the detection of ureteral calculi. Eur Radiol. 1998; 8:212-7.

40. Niall O, Russell J, MacGregor R, et al. A comparison of noncontrast computerized tomography with excretory urography in the assessment of acute flank pain. J Urol. 1999; 161:534-7.

41. Wang JH, Shen SH, Huang SS, et al. Prospective comparison of unenhanced spiral computed tomography and intravenous urography in the evaluation of acute renal colic. J Chin Med Assoc. 2008; 71:30-6.

42. Shine S. Urinary calculus: IVU vs. CT renal stone? A critically appraised topic. Abdom Imaging 2008; 33:41-3.

43. Swanson SK, Hieilman RL, Eversman WG. Urinary tract stones in pregnancy. Surg Clin North Am. 1995; 75:123.

44. Patel SJ, Reede DL, Katz DS, et al. Imaging the pregnant patient for nonobstetric conditions: algorithms and radiation dose considerations. Radiographics. 2007; 27:1705.

45. Butler EL, Cox SM, Eberts EG, et al. Symptomatic nephrolithiasis complicating pregnancy. Obstet Gynecol. 2000; 96:753.

46. Varma G, Nair N, Salim A, et al. Investigations for recognizing urinary stone. Urol Res. 2009; 37:349-52.

47. Aneela Azam, Arfan-ul-Haq,Mirza Amanullah Beg. Role of Renal Arterial Resistive Index (RI) in obstructive uropathy. J Pak Med Assoc. 2013; 63:1511.

48. Onur MR, Cubuk M, Andic C, et al. Role of resistive index in renal colic. Urol Res. 2007; 35:307-12.

49. Weiss JP, Hanno PM. Pregnancy and the Urologist. AUA update series. 1990; 9:266-271..

50. Eckford SD, Gingell JC. Ureteric obstruction in pregnancy diagnosis and management. Br J Obstet Gynaecol. 1991; 98: 1137-1140.

51. Laing FC, Benson CB, DiSalvo DN, et al. Distal ureteral calculi: Detection with vaginal US. Radiology. 1994; 192:545.

52. Mullins JK, Semins MJ, Hyams ES, et al. Half Fourier single-shot turbo spin-echo magnetic resonance urography for the evaluation of suspected renal colic in pregnancy. Urology. 2012; 79:1252-5.

53. Grenier N, Pariente JL, Trillaud H, et al. Dilatation of the collecting system during pregnancy: physiologic vs obstructive dilatation. Eur Radiol. 2000; 10:271.
54. Regan F, Bohlman ME, Khazan R, et al. MR urography using HASTE imaging in the assessment of ureteric obstruction. AJR Am J Roentgenol. 1996; 167:1115.

55. Regan F, Kuszyk B, Bohlman ME, et al. Acute ureteric calculus obstruction: unenhanced spiral CT versus HASTE MR urography and abdominal radiograph. Br J Radiol. 2005; 78:506.

56. Jellison FC, Smith JC, Heldt JP, et al. Effect of low dose radiation computerized tomography protocols on distal ureteral calculus detection. J Urol. 2009; 182:2762-7.

57. Niemann T, Kollmann T, Bongartz G. Diagnostic performance of low-dose CT for the detection of urolithiasis: a meta-analysis. AJR Am J Roentgenol. 2008; 191:396-401.

58. Hamm M, Knopfle E, Wartenberg S, et al. Low dose unenhanced helical computerized tomography for the evaluation of acute flank pain. J Urol. 2002; 167:1687.

59. White WM, Zite NB, Gash J, et al. Low-dose computed tomography for the evaluation of flank pain in the pregnant population. $J$ Endourol. 2007; 21:1255.

60. McCollough CH, Schueler BA, Atwell TD, et al. Radiation exposure and pregnancy: when should we be concerned? Radiographics. 2007; 27:909-17.

61. Spencer JA, Tomlinson AJ, Weston MJ, et al. Early report: comparison of breath-hold MR excretory urography, Doppler ultrasound and isotope renography in evaluation of symptomatic hydronephrosis of pregnancy. Clin Radiol. 2000: 55:446-53.

62. Spencer JA, Chahal R, Kelly A, et al. Evaluation of painful hydronephrosis in pregnancy: Magnetic resonance urographic patterns in physiological dilatiation versus calculous obstruction. 2004; 171: 256-8

63. Biyani CS, Joyce AD. Urolithiasis in pregnancy: II: management. BJU Int. 2002; 89:819.

64. Webb JA, Thomsen HS, Morcos SK, et al. The use of idoinated and gadolinium contrast media during pregnancy and lactation. Eur Radiol. 2005; 15:1234.

65. Irving SO, Burgess NA. Managing severe loin pain in pregnancy. BJOG. 2002; 109:1025.

66. White WM, Johnson EB, Zite NB, et al. Predictive value of current imaging modalities for the detection of urolithiasis during pregnancy: a multicenter, longitudinal study. J Urol. 2013; 189:931.

67. Skolarikos A, Laguna MP, Alivizatos G, et al. The role for active monitoring in urinary stones: a systematic review. J Endourol. 2010; 24:923-30.

68. McAleer SJ, Loughlin KR. Nephrolithiasis and pregnancy. Curr Opin Urol. 2004; 14:123-127.

69. Evans HJ, Wollin TA. The management of urinary calculi in pregnancy. Curr Opin Urol. 2001; 11:379-384.

70. Denstedt JD, Ravzi H. Management of urinary calculi during pregnancy. J Urol. 1992; 108: 1072-1075.

71. Preminger GM, Tiselius HG, Assimos DG, et al. American Urological Association Education and Research, Inc; European Association of Urology. 2007 Guideline for the management of ureteral-calculi. Eur Urol. 2007; 52:1610-31.

72. Parulkar BG, Hopkins TB, Wollin MR, et al. Renal colic during pregnancy: A case for conservative treatment. J Urol. 1998: 159:365-8.

73. Harris RE, Dunnihoo DR. The incidence of urinary calculi in pregnancy. Am J Obstet Gynecol. 1967; 99:237. 
74. Burgess KL, Gettman MT, Rangel LJ, et al. Diagnosis of urolithiasis and rate of spontaneous passage during pregnancy. J Urol. $2011 ; 186: 2280$.

75. Weber-Schoendorfer C, Hannemann D, Meister R, et al. The safety of calcium channel blockers during pregnancy: a prospective, multicenter, observational study. Reprod Toxicol. 2008; 26:24.

76. Lee SJ, Rho SK, Lee CH, et al. Management of urinary calculi in pregnant women. JKMS. 1997:12.

77. Semins MJ, Matlaga BR. Management of stone disease in pregnancy. Curr Opin Urol. 2010; 20:174.

78. Chaussy EG, Fuchs GJ. Current state and future developments of noninvasive treatment of urinary stones with ESWL. J Urol. 1989; 141:782.

79. Smith DR, Graham JB, Prystowsky JB, et al. The effects of ultrasound-guided sockwaves during early pregnancy in Sprague-Dawley rats. J Urol. 1992; 147:231.

80. Asgari MA, Safarinejad MR, Hosseini SY, Dadkhah F. Extracorporeal shock wave lithotripsy of renal calculi during early pregnancy. BJU Int. 1999:84:615-7.

81. Semins MJ, Trock BJ, Matlaga BR. The Safety of Ureteroscopy During Pregnancy: A Systematic Review and Meta-Analysis. J Urol. 2009; 181:139-143.

82. Polat F, Yesil S, Kirac M, et al. Treatment outcomes of semirigid ureterorenoscopy and intracorporeal lithotripsy in pregnant women with obstructive ureteral calculi. Urol Res. 2011; 39:487-490.

83. Travassos M, Amselem I, Filho NS, et al. Ureteroscopy in Pregnany Women for Ureteral Stone. J Endourol. 2009; 23:405-407.

84. Rana AM, Aquil S, Khawaja AM. Semirigid ureteroscopy and pneumatic litotripsy as definitive management of obstructive ureteral calculi during pregnancy. Urology. 2009; 73:964-967.

85. Bozkurt Y, Soylemez H, Atar M, et al. Effectiveness and safety of ureteroscopy in pregnant women: a comparative study. Urolithiasis. 2013; 41:37-42.

86. Johnson EB, Krambeck AE, White WM, et al. Obstetric complications of ureteroscopy during pregnancy. J Urol. 2012; 188:151154.

87. Hoscan MB, Ekinci M, Tunçkıran A, et al. Management of symptomatic ureteral calculi complicating pregnancy. Urology. 2012; 80:1011-1014.

88. Yoder IC, Lindfors KK, Pfister RC. Diagnosis and treatment of pyonephrosis. Radiol Clin North Am. 1984; 22:407-414.

89. Olivera ST, Gjulsen S, Katica Z. Obstructive nephropathy as a result of malignant neoplasms: A single centre experience. Bantao J. 2010; 8:71-4.

90. Ku JH, Lee SW, Jeon HG, et al. Percutaneous nephrostomy versus indwelling ureteral stents in the management of extrinsic ureteral obstruction in advanced malignancies: are there differences? Urology. 2004; 64:895-9.

91. Jarrard DJ, Gerber GS, Lyon ES. Management of acute ureteral obstruction in pregnancy utilizing ultrasound guided placement of ureteral stents. Urology. 1993; 42:263

92. Kavoussi LR, Albala DM, Basler JW, et al. Percutaneous management of uroltihiasis during pregnancy. J Urol. 1992; 148:1069.

93. Khoo L, Anson K, Patel U. Success and short-term complication rates of percutaneous nephrostomy during pregnancy. J Vasc Interv Radiol. 2004; 15:1469.
94. Goodwin WE, Casey WC, Woolf W. Percutaneous trocar (needle) nephrostomy in hydronephrosis. J Am Med Assoc. 1955; 157:891-894.

95. Millward SF. Percutaneous nephrostomy: a practical approach. J Vasc Interv Radiol. 2000; 11:955-964

96. Lee WJ, Patel U, Patel S, Pillari GP. Emergency percutaneous nephrostomy: results and complications. J Vasc Interv Radiol. 1994; 5:135-139

97. Venkatesan AM, Kundu S, Sacks D, et al. Practice guidelines for adult antibiotic prophylaxis during vascular and interventional radiology procedures. Written by the Standards of Practice Committee for the Society of Interventional Radiology and Endorsed by the Cardiovascular Interventional Radiological Society of Europe and Canadian Interventional Radiology Association. J Vasc Interv Radiol. 2010; 21:1611-1630.

98. Li AC, Regalado SP. Emergent percutaneous nephrostomy for the diagnosis and management of pyonephrosis. Semin Intervent Radiol. 2012; 29:218-25.

99. van Sonnenberg E, Casola G, Talner LB, et al. Symptomatic renal obstruction or urosepsis during pregnancy: treatment by sonographically guided perctaneous nephrostomy. Am J Roentgenol. 1992; 158:91-94.

100. Memon NA, Talpur AA, Memon JM. Indications and complications of indwelling ureteral stenting at NMCH, Nawabshah. Pak J Surg. 2007; 23:187-91.

101. Pearle MS, Pierce HL, Miller GL, et al. Optimal method of urgent decompression of the collecting system for obstruction and infection due to ureteral calculi. J Urol. 1998; 160:1260.

\section{Correspondence}

Orcun Celik, MD (Corresponding Autor)

orcuncelik82@hotmail.com

Hakan Türk, MD

Ozgur Cakmak, MD

Rahmi Gokhan Ekin, MD

Mehmet Zeynel Keskin, MD

Guner Yildiz, MD

Yusuf Ozlem Ilbey, MD

Tepecik Educational and Research Hospital, Urology Department

35170, Izmir, Turkey 